\title{
Serum Uric Acid Levels and Renal Impairment among ST-Segment Elevation Myocardial Infarction Patients Undergoing Primary Percutaneous Intervention
}

\author{
Yacov Shacham ${ }^{a}$ Amir Gal-Oz ${ }^{b}$ Nir Flint $^{a} \quad$ Gad Keren $^{a} \quad$ Yaron Arbel $^{a}$ \\ Departments of a Cardiology and ${ }^{b}$ Nephrology, Tel Aviv Sourasky Medical Center affiliated \\ to the Sackler Faculty of Medicine, Tel Aviv University, Tel Aviv, Israel
}

\section{Key Words}

Uric acid · Acute kidney injury · Acute myocardial infarction · Percutaneous coronary intervention

\begin{abstract}
Background: Elevated serum uric acid (UA) levels are associated with adverse outcomes in ST-segment elevation myocardial infarction (STEMI) patients undergoing primary percutaneous coronary intervention (PCI). However, the relation between UA and acute kidney injury (AKI) in this population is unclear. We evaluated the effect of elevated UA levels on the risk to develop AKI among consecutive STEMI patients treated with primary PCI. Methods: We performed a retrospective analysis of 1,372 consecutive patients admitted with the diagnosis of STEMI between January 2008 and February 2015. Patients were stratified into quartiles according to UA levels as follows: quartile $1,<4.7 \mathrm{mg} / \mathrm{dl}$; quartile $2,4.8$ to $<5.6 \mathrm{mg} / \mathrm{dl}$; quartile $3,5.7$ to $<6.6 \mathrm{mg} / \mathrm{dl}$, and quartile $4,>6.7 \mathrm{mg} / \mathrm{dl}$. Results: STEMI patients with elevated UA levels had a higher frequency of AKI ( 4 vs. $6 \%$ vs. 10 vs. $24 \%$; $<<0.001$ ). In a subgroup analysis of patients with reduced baseline estimated glomerular filtration rate $\left(\leq 60 \mathrm{ml} / \mathrm{min} / 1.73 \mathrm{~m}^{2}\right)$, an elevated UA level was associated with a significant risk to develop AKI, with $46 \%$ of patients developing AKI in the highest UA quartile. In a multivariate logistic regression model, for every $1-\mathrm{mg} / \mathrm{dl}$ increase in the UA concentration, the adjusted risk for AKI increased by $46 \%$ $(\mathrm{OR}=1.46,95 \%$ CI 1.18-1.66; $\mathrm{p}<0.001)$. Conclusions: Among STEMI patients undergoing primary PCI, elevated UA levels are an independent predictor of AKI. ๑ $2016 \mathrm{~S}$. Karger AG, Basel
\end{abstract}




\section{CardioRenal Medicine}

\section{Introduction}

Acute kidney injury (AKI) frequently complicates the course of patients presenting with ST-segment elevation myocardial infarction (STEMI) who undergo primary percutaneous coronary intervention (PCI), and is associated with adverse short- and long-term outcomes [1-4]. The levels of serum uric acid (UA), the end product of purine catabolism, have been shown to correlate with the risk for chronic kidney and ischemic heart diseases [5-9]. Elevated serum UA levels were also associated with increased short- and long-term mortality among myocardial infarction patients [10-13]. Previous studies have shown that elevated UA levels increase the risk of AKI in patients undergoing cardiac surgery $[14,15]$ and nonemergent PCI [16]. To our knowledge, there are no previous reports of the effect of UA levels on AKI in STEMI patients undergoing primary PCI, in whom preprocedural preparatory measures to reduce $A K I$ are often underutilized due to the need for emergent reperfusion therapy. In the present study, we evaluated the association of serum UA levels with the occurrence of AKI in a large cohort of consecutive STEMI patients treated with primary PCI.

\section{Materials and Methods}

We performed a retrospective, single-center observational study at the Tel Aviv Medical Center, a tertiary referral hospital with a 24/7 primary PCI service. We included 1,746 consecutive patients admitted between January 2008 and February 2015 to the Cardiac Intensive Care Unit with the diagnosis of acute STEMI. Patients who were treated either conservatively or by thrombolysis were excluded $(n=28)$, as were 63 patients whose final diagnosis on discharge was other than STEMI (e.g. myocarditis or Takotsubo cardiomyopathy). We also excluded patients who died within $24 \mathrm{~h}$ of admission $(n=16)$, since we presumed that there was insufficient time for AKI to occur, as well as patients requiring chronic peritoneal dialysis or hemodialysis treatment $(n=4)$. Finally, 263 patients without information regarding serum UA levels were also excluded from the analysis. The final study population included 1,372 patients whose baseline demographics, cardiovascular history, clinical risk factors, treatment characteristics and laboratory results were all retrieved from the hospital electronic medical records. The diagnosis of STEMI was established in accordance to published guidelines including a typical chest pain history, diagnostic electrocardiographic changes, and serial elevation of cardiac biomarkers [17]. The study protocol was approved by the local institutional ethics committee with a waiver of informed consent. Primary PCI was performed on patients with symptoms lasting for $\leq 12 \mathrm{~h}$ as well as in patients with symptoms lasting for $12-24 \mathrm{~h}$ if the symptoms persisted at the time of admission. Following coronary interventional procedures, physiologic $(0.9 \%)$ saline was given intravenously at a rate of $1 \mathrm{ml} / \mathrm{kg} / \mathrm{h}$ for $12 \mathrm{~h}$ after contrast exposure. In patients with overt heart failure, the hydration rate was reduced at the discretion of the attending physician. The contrast medium used in the procedures was iodixanol (Visipaque; GE Healthcare, Ireland) or iohexol (Omnipaque; GE Healthcare, Ireland) Left ventricular ejection fraction was assessed in all patients within the first $48 \mathrm{~h}$ of admission. Heart failure was defined as clinical or radiographic evidence of pulmonary congestion. Serum UA was collected immediately following PCI and determined by an enzymatic method using a Siemens reagent kit on a Siemens Advia 1650 instrument [18]. The serum creatinine (sCr) level was determined upon hospital admission, prior to primary PCI, and at least once a day during the Cardiac Intensive Care Unit stay and was available for all analyzed patients. The estimated glomerular filtration rate (eGFR) was estimated using the abbreviated Modification of Diet in Renal Disease equation [19]. Baseline renal insufficiency was categorized as an admission eGFR of $\leq 60 \mathrm{ml} / \mathrm{min} / 1.73 \mathrm{~m}^{2}$ [19]. AKI was determined using the AKI network criteria [20], and defined as a rise in $\mathrm{sCr}>0.3 \mathrm{mg} / \mathrm{dl}$, compared with the admission $\mathrm{sCr}$.

All data were summarized and displayed as mean \pm standard deviation for continuous variables and as number (percentage) of patients in each group for categorical variables. $p$ values for categorical variables were calculated with the $\chi^{2}$ test. Continuous variables were compared using the independent sample t test. The identification of the independent predictors of AKI was assessed by the logistic regression model using ENTER mode, adjusted for age, gender, diabetes mellitus, hypertension, eGFR, heart failure, left ventricular ejection fraction and serum UA levels. A two-tailed $p$ value of $<0.05$ was considered significant for all analyses. All analyses were performed with the SPSS software (SPSS Inc., Chicago, Ill., USA). 
Table 1. Baseline characteristics of 1,372 STEMI patients according to the serum UA quartiles

\begin{tabular}{|c|c|c|c|c|c|}
\hline \multirow[t]{2}{*}{ Variable } & \multicolumn{5}{|c|}{ Serum UA quartiles, mg/dl } \\
\hline & $\begin{array}{l}\text { quartile } 1 \\
<4.7 \\
(n=354)\end{array}$ & $\begin{array}{l}\text { quartile } 2 \\
4.8-5.6 \\
(n=338)\end{array}$ & $\begin{array}{l}\text { quartile } 3 \\
5.7-6.6 \\
(n=341)\end{array}$ & $\begin{array}{l}\text { quartile } 4 \\
>6.7 \\
(n=339)\end{array}$ & $\mathrm{p}$ \\
\hline Age, years & $61 \pm 13$ & $60 \pm 12$ & $62 \pm 12$ & $63 \pm 14$ & 0.07 \\
\hline Male gender & $233(66)$ & $286(85)$ & $289(85)$ & $293(86)$ & $<0.001$ \\
\hline Diabetes mellitus & $80(22)$ & $66(20)$ & $67(20)$ & $89(26)$ & 0.116 \\
\hline Dyslipidemia & $162(46)$ & $162(48)$ & $154(45)$ & $178(52)$ & 0.208 \\
\hline Hypertension & $129(36)$ & 131 (39) & $150(44)$ & $177(52)$ & $<0.001$ \\
\hline Smoker & $190(54)$ & $184(54)$ & $165(48)$ & $139(41)$ & $<0.001$ \\
\hline Family history of CAD & $56(16)$ & $69(20)$ & $66(19)$ & $48(14)$ & 0.105 \\
\hline Prior MI & $37(10)$ & $35(10)$ & $42(12)$ & $45(13)$ & 0.559 \\
\hline \multicolumn{6}{|c|}{ No. of narrowed coronary arteries } \\
\hline 1 & $171(48)$ & $161(48)$ & $138(40)$ & 131 (39) & 0.145 \\
\hline 2 & $92(26)$ & 99 (29) & $111(32)$ & $109(32)$ & \\
\hline 3 & $91(26)$ & $76(23)$ & $92(28)$ & $96(29)$ & \\
\hline In-hospital heart failure & $21(6)$ & $11(3)$ & $28(8)$ & $56(16)$ & $<0.001$ \\
\hline Admission CRP, mg/dl & $11.9 \pm 28.9$ & $11.6 \pm 27.6$ & $11.5 \pm 22.4$ & $15.4 \pm 28.4$ & 0.156 \\
\hline Peak CPK, U/l & $1,123 \pm 1,190$ & $1,215 \pm 1,202$ & $1,271 \pm 1,430$ & $1,532 \pm 1,995$ & 0.04 \\
\hline LV ejection fraction & $48 \pm 8$ & $48 \pm 7$ & $47 \pm 9$ & $45 \pm 8$ & 0.001 \\
\hline
\end{tabular}

Values are mean \pm standard deviation or $\mathrm{n}(\%)$. CAD = Coronary artery disease; $\mathrm{MI}=$ myocardial infarction; $\mathrm{CRP}=\mathrm{C}$-reactive protein; $\mathrm{CPK}=$ creatine phosphokinase; $\mathrm{LV}=$ left ventricle.

Table 2. AKI, sCr changes and contrast volume of 1,372 STEMI patients according to the serum UA quartiles

\begin{tabular}{|c|c|c|c|c|c|}
\hline \multirow[t]{2}{*}{ Variable } & \multicolumn{5}{|c|}{ Serum UA quartiles, mg/dl } \\
\hline & $\begin{array}{l}\text { quartile } 1 \\
<4.7 \\
(n=354)\end{array}$ & $\begin{array}{l}\text { quartile } 2 \\
4.8-5.6 \\
(n=338)\end{array}$ & $\begin{array}{l}\text { quartile } 3 \\
5.7-6.6 \\
(\mathrm{n}=341)\end{array}$ & $\begin{array}{l}\text { quartile } 4 \\
>6.7 \\
(n=339)\end{array}$ & $\mathrm{p}$ \\
\hline AKI & $16(4)$ & $21(6)$ & $33(10)$ & $83(24)$ & $<0.001$ \\
\hline Admission eGFR, ml/min $/ 1.73 \mathrm{~m}^{2}$ & $79 \pm 19$ & $75 \pm 17$ & $70 \pm 11$ & $63 \pm 20$ & $<0.001$ \\
\hline Admission eGFR $\leq 60, \mathrm{ml} / \mathrm{min} / 1.73 \mathrm{~m}^{2}$ & $45(13)$ & $54(16)$ & $82(24)$ & $121(36)$ & $<0.001$ \\
\hline Admission $\mathrm{sCr}, \mathrm{mg} / \mathrm{dl}$ & $1.02 \pm 0.17$ & $1.1 \pm 0.18$ & $1.16 \pm 0.23$ & $1.29 \pm 0.35$ & $<0.001$ \\
\hline Peak sCr, mg/dl & $1.05 \pm 0.42$ & $1.11 \pm 0.27$ & $1.19 \pm 0.41$ & $1.48 \pm 0.73$ & $<0.001$ \\
\hline sCr change in-hospital, mg/dl & $0.02 \pm 0.42$ & $0.01 \pm 0.22$ & $0.04 \pm 0.32$ & $0.18 \pm 52$ & $<0.001$ \\
\hline $\mathrm{sCr}$ at discharge, $\mathrm{mg} / \mathrm{dl}$ & $0.99 \pm 0.17$ & $1.06 \pm 0.21$ & $1.12 \pm 0.37$ & $1.32 \pm 0.52$ & $<0.001$ \\
\hline Contrast material amount, $\mathrm{ml}$ & $149 \pm 18$ & $134 \pm 17$ & $141 \pm 22$ & $132 \pm 52$ & 0.361 \\
\hline
\end{tabular}

Values are $\mathrm{n}(\%)$ or mean \pm standard deviation.

\section{Results}

The study population included 1,372 patients (mean age $61 \pm 13$ years, 81\% males). Quartiles of UA concentrations were as follows: quartile $1,<4.7 \mathrm{mg} / \mathrm{dl}$; quartile $2,4.8$ to $<5.6$ $\mathrm{mg} / \mathrm{dl}$; quartile 3, 5.7 to $<6.6 \mathrm{mg} / \mathrm{dl}$, and quartile $4,>6.7 \mathrm{mg} / \mathrm{dl}$. The baseline characteristics of patients according to UA quartiles are presented in table 1. Patients with higher UA levels were more likely to be older, of male gender, hypertensive, more likely to develop heart failure throughout hospitalization, and to have a lower left ventricular ejection fraction. 


\section{CardioRenal Medicine}

Fig. 1. Incidence of AKI according to serum UA quartiles and baseline eGFR. * p value for the comparison of the upper quartile with the other quartiles.

Table 3. Binary logistic regression models for AKI prediction

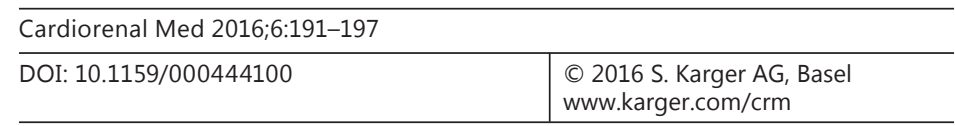

Shacham et al.: Serum UA Levels and Renal Impairment among STEMI Patients Undergoing Primary Percutaneous Intervention

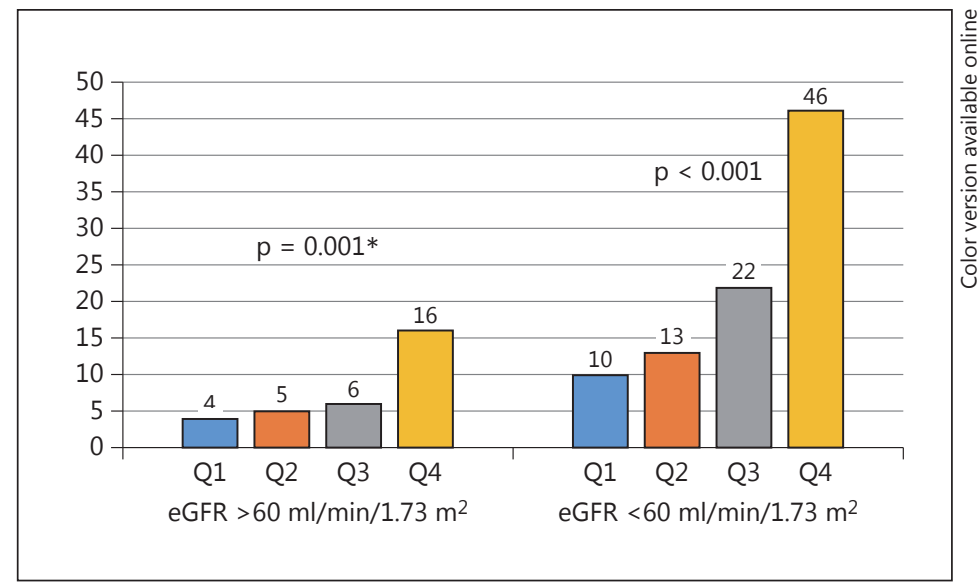

\begin{tabular}{llll}
\hline Correlates & OR & $95 \%$ CI & $\mathrm{p}$ \\
\hline Age & 1.02 & $0.99-1.05$ & 0.07 \\
Male gender & 1.33 & $0.81-2.21$ & 0.261 \\
Diabetes mellitus & 1.13 & $0.72-1.75$ & 0.603 \\
Hypertension & 1.92 & $1.25-2.96$ & 0.003 \\
eGFR $\leq 60\left(\mathrm{ml} / \mathrm{min} / 1.73 \mathrm{~m}^{2}\right)$ & 1.67 & $1.02-2.75$ & 0.04 \\
LV ejection fraction & 0.95 & $0.92-0.99$ & 0.001 \\
Heart failure & 2.74 & $1.64-4.57$ & 0.001 \\
Serum UA (1-mg/dl increase) & 1.46 & $1.18-1.66$ & 0.001 \\
\hline
\end{tabular}

$\mathrm{LV}=$ Left ventricular.

Following primary PCI, AKI occurred in 153 (11\%) patients. Table 2 compares the occurrence of $\mathrm{AKI}$ and $\mathrm{s} \mathrm{Cr}$ changes between the UA levels. Patients having elevated UA levels had more AKI, complicating the course of STEMI ( 4 vs. $6 \%$ vs. 10 vs. $24 \%$; $<<0.001$ ). Two patients required renal replacement therapy; both had UA levels in the upper quartile. No significant difference was present between groups regarding the amount of contrast volume delivered during PCI. In subgroup analysis, the incidence of AKI was found to be related to baseline eGFR in all UA quartiles, with increased AKI incidence among patients with lower baseline eGFR. Among the 302 patients with baseline eGFR $\leq 60 \mathrm{ml} / \mathrm{min} / 1.73 \mathrm{~m}^{2}$, the incidence of AKI demonstrated a graded increase between the UA quartiles (10 vs. $13 \%$ vs. 22 vs. $46 \%$; p < 0.001 ; fig. 1). Among the 1,070 patients with baseline eGFR $>60 \mathrm{ml} / \mathrm{min} / 1.73 \mathrm{~m}^{2}$, those in the upper UA quartile demonstrated a significant increase in the incidence of AKI compared with the lower 3 quartiles ( 4 vs. $5 \%$ vs. 6 vs. 16\%; p =0.001; fig. 1). In a multivariate logistic regression model, the risk for AKI increased by $46 \%$ for every $1-\mathrm{mg} / \mathrm{dl}$ increase in UA (OR = $1.46,95 \%$ CI 1.18-1.66; $\mathrm{p}<0.001$ ). Other predictors for AKI included hypertension, eGFR $\leq 60$ $\mathrm{ml} / \mathrm{min} / 1.73 \mathrm{~m}^{2}$, left ventricular ejection fraction, and heart failure (table 3 ).

\section{Discussion}

In the current study, we have investigated the association of serum UA levels with the occurrence of AKI in a large cohort of consecutive STEMI patients undergoing primary PCI. For every $1-\mathrm{mg} / \mathrm{dl}$ increase in UA level, the adjusted risk for AKI was increased by $46 \%$. 
Shacham et al.: Serum UA Levels and Renal Impairment among STEMI Patients Undergoing Primary Percutaneous Intervention

Subgroup analysis demonstrated that patients with reduced baseline eGFR $(\leq 60 \mathrm{ml} / \mathrm{min}$ / $1.73 \mathrm{~m}^{2}$ ) and elevated UA levels had the highest risk to develop AKI, reaching an incidence of $46 \%$ in the highest quartile.

Several reports demonstrated that among patients with myocardial infarction, serum UA levels correlated closely with in-hospital complications and predicted the development of congestive heart failure as well as short- and long-term mortality [10-13]. The impact relation of UA on adverse outcomes in these patients was present in all degrees of renal dysfunction including patients who developed contrast-induced nephropathy [13]. These observations were related to both the association of UA with adverse cardiovascular risk profile as well as to direct pro-oxidant [21] and pro-inflammatory actions [22]. An elevated serum UA level has been reported to be an independent risk factor for the development of chronic kidney disease [7-9]; however, limited data is available regarding its relation to AKI. Recent data suggested that elevated UA levels increase the risk of AKI in patients undergoing cardiac surgery [14, 15]. A report by Park et al. [16] demonstrated that among patients undergoing PCI, those with AKI had higher UA levels, and that UA was independently associated with the risk for AKI. Nonetheless, in that cohort, only a minority of patients had myocardial infarction with emergency PCI, and the incidence of AKI was significantly reduced, compared to the rate that we demonstrated in our cohort (4 vs. 11\%).

There are several possible explanations for the effect of UA on the development of AKI. Hyperuricemia inhibits the nitric oxide system in the kidneys and increases endothelin-1 concentrations, resulting in loss of renal blood flow autoregulation, renal vasoconstriction and reduced medullary blood flow [23, 24]. Hyperuricemia was also shown to stimulate the expression of C-reactive protein [25] and induce the infiltration of inflammatory cells into the renal parenchyma with resultant tissue injury $[22,25]$.

We have recently suggested that the mechanism of AKI in STEMI seems to be associated with an acute hemodynamic instability [26], resulting in decreased renal perfusion. Elevated UA levels may thus form a synergistic effect, further reducing renal perfusion, exacerbating ischemia/reperfusion injury, further aggravating the ischemic insult to the kidney, with the result of greater susceptibility to AKI. Indeed, the finding of no significant difference in the amount of contrast material used among those with and without AKI in our cohort further implicates the importance of UA in this setting.

Our study carries important clinical implications. As the treatment of post-PCI AKI is rather limited and hydration prior to primary PCI is rarely performed, the main strategy is identification of those at risk to develop this complication.

The addition of simple and early measurements of serum UA to other established clinical risk factors may be useful for early identification of those at high risk for post-PCI AKI (e.g. those with a baseline eGFR $\leq 60 \mathrm{ml} / \mathrm{min} / 1.73 \mathrm{~m}^{2}$ ), warranting more frequent monitoring of urinary output, which has been shown to enable earlier detection of renal function impairment [27]. Previous studies have demonstrated improvement of endothelial function in patients with hyperuricemia and heart failure or diabetes who received allopurinol [28]. Since allopurinol treatment is associated with severe hypersensitivity reactions, there is no sufficient evidence to support treatment of asymptomatic hyperuricemia with this drug. In addition, a recent report has shown that lowering serum UA levels with rasburicase provides no benefit to postoperative $\mathrm{s} C \mathrm{r}$ in hyperuricemic subjects undergoing cardiac surgery [29]. It is thus not clear whether an elevated UA level contributes per se to renal injury or is simply a marker for increased AKI risk.

We acknowledge several important limitations of our study. First, this was a single-center retrospective and nonrandomized observational study, and may have been subject to bias. Patients with higher UA levels had other comorbid conditions (i.e. hypertension and decreased ejection fraction) associated with impaired vascular/renal perfusion, which may have led to 
Shacham et al.: Serum UA Levels and Renal Impairment among STEMI Patients

Undergoing Primary Percutaneous Intervention

worsening of renal function on contrast exposure. Nevertheless, we attempted to adjust for these confounding factors using the multivariate regression model. Second, information regarding the amount of contrast material used was available in only 418 patients. We showed, however, that in those patients, no significant changes were found regarding contrast volume between the different UA quartiles. The definition of AKI network criteria refers to $\mathrm{sCr}$ change within a time frame of $48 \mathrm{~h}$ [20]. As the change in $\mathrm{sCr}$ can lag beyond this period due to delayed effects of contrast material and drugs [2-4], worsening of renal function might have occurred following hospital discharge in some patients, thus the true incidence of AKI described in our study may have been underestimated.

No information was present regarding failed PCI, which might have affected the occurrence of acute heart failure. Patients with elevated serum UA levels were more likely to have hypertension and may have been subjected to prior treatment with diuretics. Since no information was available on the use of diuretics prior to admission, their possible effect on UA levels could not been assessed. Finally, since no information about allopurinol treatment was available, the impact of this drug on the risk of AKI could not have been assessed.

In conclusion, among STEMI patients undergoing primary PCI, serum UA levels were found to be associated with a higher rate of AKI. It appears that patients with both preexisting moderate renal insufficiency (eGFR $\leq 60 \mathrm{ml} / \mathrm{min} / 1.73 \mathrm{~m}^{2}$ ) and hyperuricemia are at the highest risk for developing AKI.

\section{Disclosure Statement}

The authors have no conflicts of interest to disclose.

\section{References}

1 Shacham Y, Leshem-Rubinow E, Steinvil A, Assa EB, Keren G, Roth A, Arbel Y: Renal impairment according to acute kidney injury network criteria among ST elevation myocardial infarction patients undergoing primary percutaneous intervention: a retrospective observational study. Clin Res Cardiol 2014;103:525-532.

2 Goldberg A, Hammerman H, Petcherski S, Zdorovyak A, Yalonetsky S, Kapeliovich M, Agmon Y, Markiewicz W, Aronson D: Inhospital and 1-year mortality of patients who develop worsening renal function following acute ST-elevation myocardial infarction. Am Heart J 2005;150:330-337.

3 Parikh CR, Coca SG, Wang Y, Masoudi FA, Krumholz HM: Long-term prognosis of acute kidney injury after acute myocardial infarction. Arch Intern Med 2008;168:987-995.

4 Amin AP, Spertus JA, Reid KJ, Lan X, Buchanan DM, Decker C, Masoudi FA: The prognostic importance of worsening renal function during an acute myocardial infarction on long-term mortality. Am Heart J 2010;160: 1065-1071.

5 Feig DI, Kang DH, Johnson RJ: Uric acid and cardiovascular risk. N Engl J Med 2008;359:1811-1821.

6 Short RA, Johnson RJ, Tuttle KR: Uric acid, microalbuminuria and cardiovascular events in high-risk patients. Am J Nephrol 2005;25:36-44.

7 Kang DH, Nakagawa T: Uric acid and chronic renal disease: possible implication of hyperuricemia on progression of renal disease. Semin Nephrol 2005;25:43-49.

8 Madsen TE, Muhlestein JB, Carlquist JF, Horne BD, Bair TL, Jackson JD, Lappe JM, Pearson RR, Anderson JL: Serum uric acid independently predicts mortality in patients with significant, angiographically defined coronary disease. Am J Nephrol 2005;25:45-49.

9 Dincer HE, Dincer AP, Levinson DJ: Asymptomatic hyperuricemia: to treat or not to treat. Cleve Clin J Med 2002;69:594-608.

10 Kojima S, Sakamoto T, Ishihara M, Kimura K, Miyazaki S, Yamagishi M, Tei C, Hiraoka H, Sonoda M, Tsuchihashi K, Shimoyama N, Honda T, Ogata Y, Matsui K, Ogawa H; Japanese Acute Coronary Syndrome Study (JACSS) Investigators: Prognostic usefulness of serum uric acid after acute myocardial infarction (the Japanese Acute Coronary Syndrome Study). Am J Cardiol 2005;96:489-495.

11 Lazzeri C, Valente S, Chiostri M, Sori A, Bernardo P, Gensini GF: Uric acid in the acute phase of ST elevation myocardial infarction submitted to primary PCI: its prognostic role and relation with inflammatory markers: a single center experience. Int J Cardiol 2010;138:206-209.

12 Lazzeri C, Valente S, Chiostri M, Picariello C, Gensini GF: Uric acid in the early risk stratification of ST-elevation myocardial infarction. Intern Emerg Med 2012;7:33-39. 
Shacham et al.: Serum UA Levels and Renal Impairment among STEMI Patients

Undergoing Primary Percutaneous Intervention

13 Kowalczyk J, Francuz P, Swoboda R, Lenarczyk R, Sredniawa B, Golda A, Kurek T, Mazurek M, Podolecki T, Polonski L, Kalarus Z: Prognostic significance of hyperuricemia in patients with different types of renal dysfunction and acute myocardial infarction treated with percutaneous coronary intervention. Nephron Clin Pract 2010;116:c114-c122.

14 Ejaz AA, Beaver TM, Shimada M, Sood P, Lingegowda V, Schold JD, Kim T, Johnson RJ: Uric acid: a novel risk factor for acute kidney injury in high-risk cardiac surgery patients? Am J Nephrol 2009;30:425-429.

15 Lapsia V, Johnson RJ, Dass B, Shimada M, Kambhampati G, Ejaz NI, Arif AA, Ejaz AA: Elevated uric acid increases the risk for acute kidney injury. Am J Med 2012;125:302.e9-e17.

16 Park SH, Shin WY, Lee EY, Gil HW, Lee SW, Lee SJ, Jin DK, Hong SY: The impact of hyperuricemia on in-hospital mortality and incidence of acute kidney injury in patients undergoing percutaneous coronary intervention. Circ J 2011;75:692-697.

17 O'Gara PT, Kushner FG, Ascheim DD, Casey DE Jr, Chung MK, de Lemos JA, Ettinger SM, Fang JC, Fesmire FM, Franklin BA, Granger CB, Krumholz HM, Linderbaum JA, Morrow DA, Newby LK, Ornato JP, Ou N, Radford MJ, Tamis-Holland JE, Tommaso CL, Tracy CM, Woo YJ, Zhao DX, Anderson JL, Jacobs AK, Halperin JL, Albert NM, Brindis RG, Creager MA, DeMets D, Guyton RA, Hochman JS, Kovacs RJ, Ohman EM, Stevenson WG, Yancy CW: 2013 ACCF/AHA guideline for the management of ST-elevation myocardial infarction: a report of the American College of Cardiology Foundation/American Heart Association Task Force on Practice Guidelines. J Am Coll Cardiol 2012;61:e78-e140.

18 Fossati P, Prencipe L, Berti G: Use of 3,5-dichloro-2-hydroxybenzenesulfonic acid/4-aminophenazone chromogenic system in direct enzymic assay of uric acid in serum and urine. Clin Chem 1980;26:227-231.

19 Levey AS, Bosch JP, Lewis JB, Greene T, Rogers N, Roth D: A more accurate method to estimate glomerular filtration rate from serum creatinine: a new prediction equation. Modification of diet in renal disease study group. Ann Intern Med 1999;130:461-470.

20 National Kidney Foundation: K/DOQI clinical practice guidelines for chronic kidney disease: evaluation, classification, and stratification. Am J Kidney Dis 2002;39:S1-S266.

21 Ogino K, Kato M, Furuse Y, Kinugasa Y, Ishida K, Osaki S, Kinugawa T, Igawa O, Hisatome I, Shigemasa C, Anker SD, Doehner W: Uric acid-lowering treatment with benzbromarone in patients with heart failure: a doubleblind placebo-controlled crossover preliminary study. Circ Heart Fail 2010;3:73-81.

22 Ruggiero C, Cherubini A, Ble A, Bos AJ, Maggio M, Dixit VD, Lauretani F, Bandinelli S, Senin U, Ferrucci L: Uric acid and inflammatory markers. Eur Heart J 2006;27:1174-1181.

23 Perlstein TS, Gumieniak O, Hopkins PN, Murphey LJ, Brown NJ, Williams GH, Williams GH, Hollenberg NK, Fisher ND: Uric acid and the state of the intrarenal renin-angiotensin system in humans. Kidney Int 2004;66: 1465-1470.

24 Ejaz AA, Mu W, Kang DH, Roncal C, Sautin YY, Henderson G, Tabah-Fisch I, Keller B, Beaver TM, Nakagawa T, Johnson RJ: Could uric acid have a role in acute renal failure? Clin J Am Soc Nephrol 2007;2:16-21.

25 Kang DH, Park SK, Lee IK, Johnson RJ: Uric acid-induced C-reactive protein expression: implication on cell proliferation and nitric oxide production of human vascular cells. J Am Soc Nephrol 2005;16:3553-3562.

26 Shacham Y, Leshem-Rubinow E, Gal-Oz A, Arbel Y, Keren G, Roth A, Steinvil A: Acute cardio-renal syndrome as a cause for renal deterioration among myocardial infarction patients treated by primary percutaneous intervention. Can J Cardiol 2015;31:1240-1244.

27 Shacham Y, Rofe M, Leshem-Rubinow E, Gal-Oz A, Arbel Y, Keren G, Roth A, Ben-Assa E, Halkin A, Finkelstein A, Banai S, Steinvil A: Usefulness of urine output criteria for early detection of acute kidney injury after transcatheter aortic valve implantation. Cardiorenal Med 2014;4:155-160.

28 George J, Carr E, Davies J, Belch JJ, Struthers A: High-dose allopurinol improves endothelial function by profoundly reducing vascular oxidative stress and not by lowering uric acid. Circulation 2006;114:25082516.

29 Ejaz AA, Dass B, Lingegowda V, Shimada M, Beaver TM, Ejaz NI, Abouhamze AS, Johnson RJ: Effect of uric acid lowering therapy on the prevention of acute kidney injury in cardiovascular surgery. Int Urol Nephrol 2013; 45:449-458. 